\title{
WELD SOLIDIFICATION BEHAVIOR OF NI-BASE SUPERALLOYS FOR USE IN ADVANCED SUPERCRITICAL COAL-FIRED POWER PLANTS
}

\author{
David C. Tung ${ }^{1}$, John C. Lippold ${ }^{1}$ \\ ${ }^{1}$ The Ohio State University. 1248 Arthur E. Adams Dr. Columbus, Ohio 43221. USA
}

Keywords: Welding Metallurgy, Solidification, Inconel 740H, AUSC coal-fired power plants

\begin{abstract}
Due to a unique combination of elevated-temperature strength and corrosion resistance, Alloy $740 \mathrm{H}$ is a leading candidate for the construction of Advanced Ultra Supercritical coal-fired power plants. To date, virtually no information regarding the solidification behavior of this alloy is available. In this investigation, the weld metal of Alloy $740 \mathrm{H}$ and candidate filler metals Haynes 282 and Nimonic 263 diluted by $740 \mathrm{H}$ were studied. Computational modeling was used to determine solidification temperature ranges and partition coefficients of these combinations. Small samples of Alloy $740 \mathrm{H}$ and mixtures of $740 \mathrm{H}$ with filler metals 282 and 263 were cast into small buttons which were used to collect solidification temperature range data. Actual gas tungsten arc welds on $740 \mathrm{H}$ plate were compared to the solidification data and computational modeling results. Characterization of these welds after heat treatment revealed $\gamma^{\prime}$ free zones which were previously thought to exist only after creep testing. The effect of postweld heat treatment on the microstructure and properties of $740 \mathrm{H}$ weld metal was also investigated.
\end{abstract}

\section{Introduction}

There is currently a strong incentive to increase the operating temperature and pressure of steam in coal-fired power plants in order to improve plant efficiency and reduce emissions. Target steam conditions are $760^{\circ} \mathrm{C}\left(1400^{\circ} \mathrm{F}\right), 35 \mathrm{MPa}(5000 \mathrm{psi})$ [1] for plants that are designated Advanced Ultra Super Critical (AUSC) due to the significantly higher steam temperature and pressure relative to conventional plants. These advanced conditions could increase cycle efficiency by as much as $13 \%$ over USC plants [2]. AUSC conditions are beyond the engineering capability of 9-12 $\mathrm{Cr}$ steels and other materials that are commonly used in coal-fired plants [2], as shown in Figure 1. For this reason, advanced materials such as $\gamma^{\prime}$ strengthened Ni-base superalloys, such as INCONEL ${ }^{\mathrm{TM}} 740 \mathrm{H}$, are required. INCONEL ${ }^{\mathrm{TM}} 740$ was developed as a derivative of Nimonic 263 by Special Metals Corporation [3] and has been found to have superior high temperature strength and corrosion resistance relative to other $\mathrm{Ni}$ base alloys under consideration [1].

INCONEL ${ }^{\mathrm{TM}} 740$ was modified to reduce deleterious phase formation $(\eta)$ and mitigate weld metal cracking; the modified composition is called INCONEL ${ }^{\text {TM }} 740 \mathrm{H}^{1}$. However, $740 \mathrm{H}$ suffers a weld strength reduction factor (WSRF) of $25 \%$ at AUSC temperatures after a single step postweld heat treatment (PWHT) [4]. It has been determined that an excellent microstructure can be obtained after two high temperature (solutionizing) steps

\footnotetext{
${ }^{1}$ For the remainder of the paper, INCONEL ${ }^{\mathrm{TM}} 740 \mathrm{H}$ will be referred to as Alloy $740 \mathrm{H}$ or simply $740 \mathrm{H}$
}

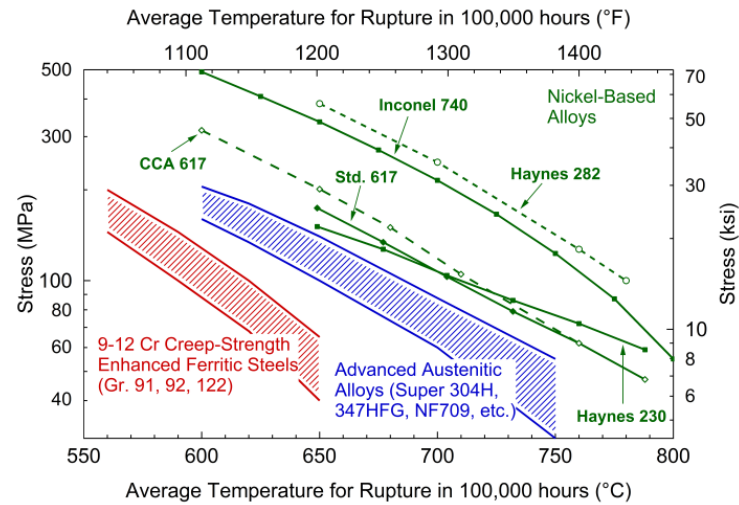

Figure 1. 100,000 hr creep rupture data [1]. A minimum strength of $100 \mathrm{MPa}$ is desired at the temperature of AUSC application [5].

followed by aging [6] but such heat treatments are usually not feasible for construction of large power plant components and would certainly not be economical. Therefore, it is desirable to consider simpler heat treatments to optimize creep rupture properties that can be used after welding.

Virtually no information regarding the weld solidification behavior of Alloy $740 \mathrm{H}$ is available, and therefore a baseline must be established for understanding the weld microstructure, and ultimately, the performance of this alloy in high temperature service. In this study, computational techniques were used to determine the solidification temperature range and the extent of alloying element redistribution during solidification (segregation). The solidification temperature range was experimentally measured at cooling rates representative of those that occur during welding using single sensor differential thermal analysis (SS $\left.\mathrm{DTA}^{\mathrm{TM}}\right) .[7,8]$ Microhardness and X-ray Energy Dispersive Spectroscopy (XEDS) measurements were made on bead-on-plate welds. Microstructural characterization was conducted using the Scanning Electron Microscope (SEM) following special preparation using a newly developed etchant. In addition to Alloy $740 \mathrm{H}, 282$ and 263 were evaluated as candidate filler metals for Alloy $740 \mathrm{H}$ base metal. The nominal compositions of these alloys are provided in Table I.

Table I. Nominal alloy compositions (wt\%) with balance Ni [4].

\begin{tabular}{ccccccccccc}
\hline & Cr & Co & Mo & Al & Ti & Nb & Fe & C & Si & B \\
\hline $\mathbf{7 4 0}$ & 25 & 20 & 0.5 & 0.9 & 1.8 & 2.0 & 0.7 & 0.03 & 0.5 & 0.003 \\
$\mathbf{7 4 0 H}$ & 25 & 20 & 0.5 & 1.4 & 1.4 & 1.5 & 1.0 & 0.03 & 0.2 & 0.001 \\
$\mathbf{2 8 2}$ & 20 & 10 & 8.5 & 1.5 & 2.1 & - & 1.5 & 0.06 & 0.15 & 0.005 \\
$\mathbf{2 6 3}$ & 20 & 20 & 5.8 & 0.6 & 2.2 & - & 0.7 & 0.06 & 0.4 & 0.005 \\
\hline
\end{tabular}




\section{Experimental Procedures}

\section{$\underline{\text { ThermoCalc Scheil Module }}$}

Using the Scheil module of ThermoCalc with nickel database TTNI7, the solidification temperature range and partition coefficient were calculated for the nominal compositions of the alloys in this study. Dilutions of Alloys 282 and 263 by $740 \mathrm{H}$ were studied in $10 \%$ increments. The solidification temperature range (STR), which can sometimes be used to evaluate an alloy's susceptibility to weld solidification cracking, is simply determined by the difference between the solidus and liquidus temperatures. Solidus temperatures were calculated over a $4 \%$ range of terminal fraction solidified $\left(f_{s}=95 \%-99 \%\right)$. It is necessary to choose a final fraction solid due to the asymptotic nature of the Scheil equation. Liquidus temperatures are independent of the terminal fraction solidified.

The partition coefficient can be calculated from the same Scheil module data that is used to determine the STR, but it is done for $1 \%$ fraction solid (beginning of solidification). The partition coefficient, $\mathrm{k}$, is formally defined as the composition of the solid, $\mathrm{C}_{\mathrm{s}}$, divided by the composition of the liquid, $\mathrm{C}_{\mathrm{l}}:\left(k=\frac{C_{s}}{C_{l}}\right)$. For linear liquidus and solidus lines, this ratio is constant with respect to temperature. However, for $\mathrm{f}_{\mathrm{s}}=1 \%$, the composition of the liquid is close to the nominal composition, $\mathrm{C}_{0}$, and in these calculations $\mathrm{C}_{1}$ is approximated with $\mathrm{C}_{0}$.

\section{Button Melting}

Solidification temperature ranges were measured at cooling rates representative of actual welding conditions using a calculationbased single sensor differential thermal analysis (SS DTA) technique. SS DTA software calculates a reference cooling curve and fits it to experimental data. This allows phase transformation temperatures to be determined in a similar fashion as traditional differential thermal analysis (DTA), but only requires a single temperature measurement [7]. Cooling curves were collected by plunging a type $\mathrm{C}$ thermocouple into a molten spot weld on a small button-shaped sample immediately after the arc was extinguished. Figure 2 schematically illustrates the method by which cooling rate data was collected. Buttons were cast by melting filler wire with a tungsten electrode over a copper hearth under an argon atmosphere. The cooling rate is determined by the size of the sample; 20 gram buttons were used in this study. The effects of dilution were studied by controlling the mass of filler wire of each alloy that was used to create a button (e.g., 30\% dilution $=6 \mathrm{~g}$ base metal $+14 \mathrm{~g}$ filler metal). Dilutions of both 282 and 263 by $740 \mathrm{H}$ were studied in $10 \%$ increments over the entire range of pure filler metal to pure base metal.

\section{Welding Procedure}

Bead-on-plate welds were made for characterization and heat treatment. Welds were made on annealed $740 \mathrm{H}$ base plate (Heat HV1369A) (0.5 x $5.5 \times 12$ in.) supplied by the Babcock and Wilcox Company with filler metals of 282 (Heat 2082-6-8356), 263 (Cast ANJ 2990, Batch 37314), and 740H (Heat HV1219). The automated gas tungsten arc welding was done under $100 \% \mathrm{Ar}$ shielding with parameters of 185 amps, 11.4 volts, and a travel speed of 3-4 ipm. These parameters are comparable to those used by Smith, et al. in their evaluation of Alloy 740H [9].

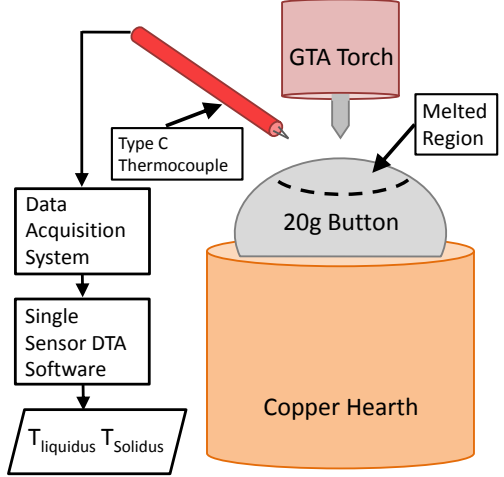

Figure 2. Schematic of the SS DTA data collection technique.

After sectioning, polishing, and electrolytically etching with oxalic acid, hardness traverses were made through the weld metal and heat affected zone (HAZ) into the base metal. Parallel, staggered traverses were made with $500 \mathrm{~g}$ Vicker's indents at a spacing of $0.25 \mathrm{~mm}$. Hardness testing was performed on welds in both the as-welded and heat treated condition. Heat treatment schedules are shown in Table II.

Table II. Heat Treatment Schedules.

\begin{tabular}{lll}
\hline Heat Treatment & Step 1 & Step 2 \\
\hline As-Welded & - & - \\
Direct Age & $800^{\circ} \mathrm{C} / 4 \mathrm{~h} / \mathrm{AC}$ & - \\
Light Anneal + Age & $1010^{\circ} \mathrm{C} / 2 \mathrm{~h} / \mathrm{AC}$ & $800^{\circ} \mathrm{C} / 4 \mathrm{~h} / \mathrm{AC}$ \\
'Solution' Anneal + Age & $1135^{\circ} \mathrm{C} / 1 \mathrm{~h} / \mathrm{AC}$ & $800^{\circ} \mathrm{C} / 4 \mathrm{~h} / \mathrm{AC}$ \\
High T Anneal & $1204^{\circ} \mathrm{C} / 4 \mathrm{~h} / \mathrm{FC}$ & - \\
\hline
\end{tabular}

The welds that had previously been subjected to creep testing were initially aged with the direct age PWHT [4]. This is the condition that produced unsatisfactory weld metal creep rupture data with unacceptable strength reduction factors. The light anneal and solution annealing treatments were intended to improve weld metal homogeneity before aging.

\section{Characterization}

Re-polished samples were examined in the SEM in the aspolished condition in order to be suitable for XEDS. Linear scans were made perpendicular to the dendrite growth direction in order to measure composition changes across the dendrites.

Finally, an electrolytic matrix etch $\left(15 \mathrm{~g} \mathrm{CrO}_{3}, 150 \mathrm{~mL} \mathrm{H}_{3} \mathrm{PO}_{4}, 20\right.$ $\mathrm{mL} \mathrm{H}_{2} \mathrm{SO}_{4}$ ) was applied for characterization in the SEM using a through lens detector. This etching technique attacks the matrix and reveals any precipitates in the microstructure. The through lens detector enabled characterization at magnifications up to $200,000 \mathrm{X}$.

\section{Results}

Calculated and experimentally measured solidus temperatures for the entire range of dilution are compared in Figure 3. The experimental solidus data, which are averages of 3 tests, generally lie within the range of $95 \%-99 \% \mathrm{f}_{\mathrm{s}}$. Based on SS DTA data, the solidus temperatures appear to increase as the $740 \mathrm{H}$ composition is approached $(100 \%$ dilution by $740 \mathrm{H})$. Calculated liquidus 
temperatures are also shown. Since experimental data is not collected until after the arc is extinguished, the liquidus temperature is generally not observed during the SS DTA cooling curve analysis. Previous experience with other Ni-base alloys has shown that when experimental liquidus temperatures are detected, they tend to be very close to calculated liquidus temperatures. For this reason, only calculated liquidus data is shown in Figure 3. Thus, the general trend for both the 282 and 263 filler metals is for a decrease in solidification temperature range as dilution by the $740 \mathrm{H}$ base metal increases. Figure 3 also indicates that the measured solidus temperatures are most representative for the Scheil simulations that stop at $95 \% \mathrm{f}_{\mathrm{s}}$.

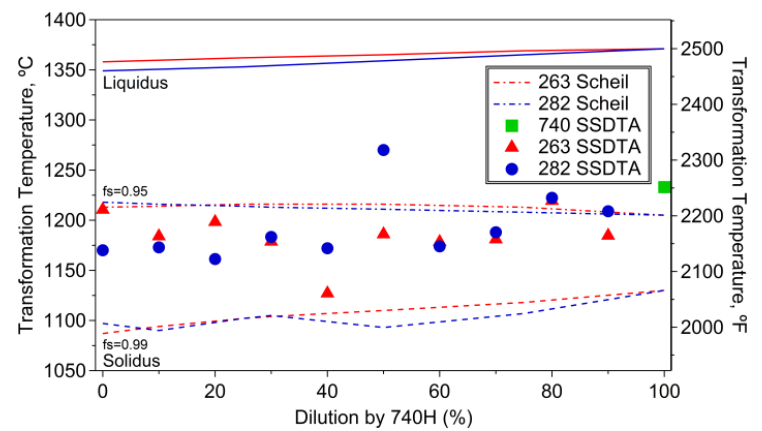

Figure 3. Comparison of calculated and experimentally measured solidus temperatures for the entire range of dilution.

Hardness traverses in the as-welded and direct aged conditions are presented in Figure 4. As expected, significant hardening occurs in the HAZ and weld metal. No significant difference in aging response is evident among the three filler metals.

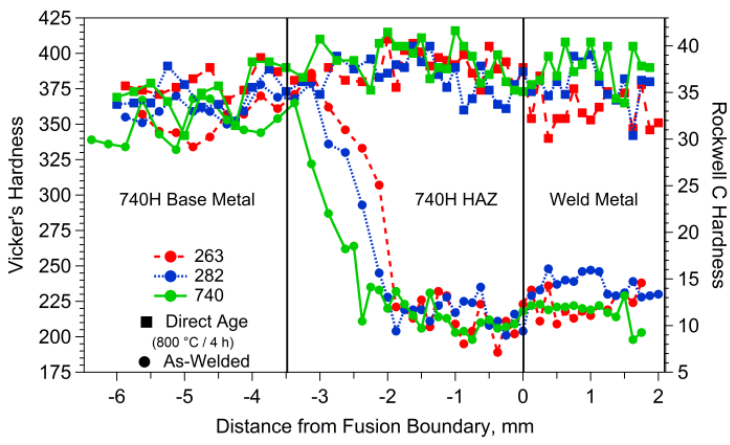

Figure 4. Hardness traverse data for the as-welded and direct-age heat treatment conditions for all three alloys in this study. The direct age PWHT restores hardness to base metal levels for all alloys.

Calculated solidification partition coefficients for the three filler metals (undiluted) are shown in Figure 5. Many of the alloying elements ( $\mathrm{Al}, \mathrm{Fe}, \mathrm{Co}$, and $\mathrm{Cr}$ ) have partition coefficients very close to unity, which indicates almost no tendency for segregation during solidification. Mo, $\mathrm{Ti}$, and $\mathrm{Si}$ exhibit a moderate tendency for segregation to the cell/dendrite boundaries, while $\mathrm{Nb}, \mathrm{C}$, and $\mathrm{B}$ are expected to segregate strongly.

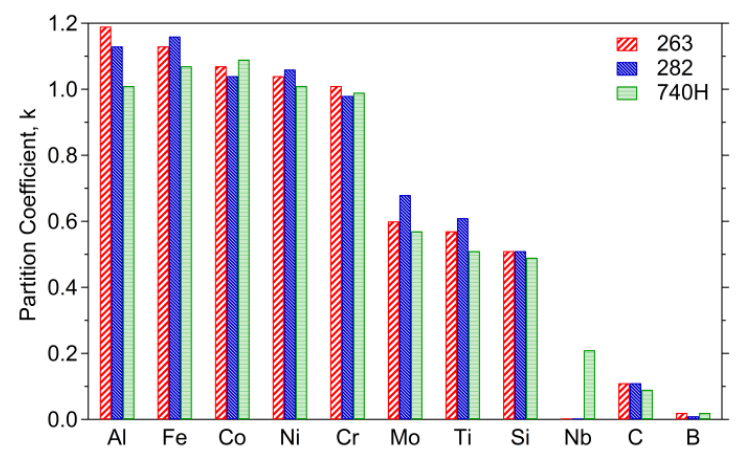

Figure 5. Calculated partition coefficients (k). Only Alloy $740 \mathrm{H}$ contains $\mathrm{Nb}$. When $\mathrm{k} \approx 1$ there is minimal segregation. For $\mathrm{k}>1$, the alloying element will segregate towards the dendrite core and for $\mathrm{k}<1$, segregation occurs toward the dendrite boundary.

SEM/XEDS measurements of $\mathrm{Al}, \mathrm{Ti}$, and $\mathrm{Nb}$ distribution in Alloy $740 \mathrm{H}$ weld metal is shown in Figure 6. The sharp increases in Ti and $\mathrm{Nb}$ represent cell/dendrite boundaries. The very high peaks in $\mathrm{Ti}$ and $\mathrm{Nb}$ result from XEDS analysis at a boundary location where a $(\mathrm{Ti}, \mathrm{Nb})$-rich carbide was present. A comparison of the calculated and experimental $\mathrm{k}$-values for $\mathrm{Al}, \mathrm{Ti}$, and $\mathrm{Nb}$ is provided in Table III. Although the absolute values differ, the trends are consistent. Most importantly, significant local variations in $\mathrm{Ti}$ and $\mathrm{Nb}$ are both predicted and measured. As discussed below, this can influence the aging behavior of the weld metal.
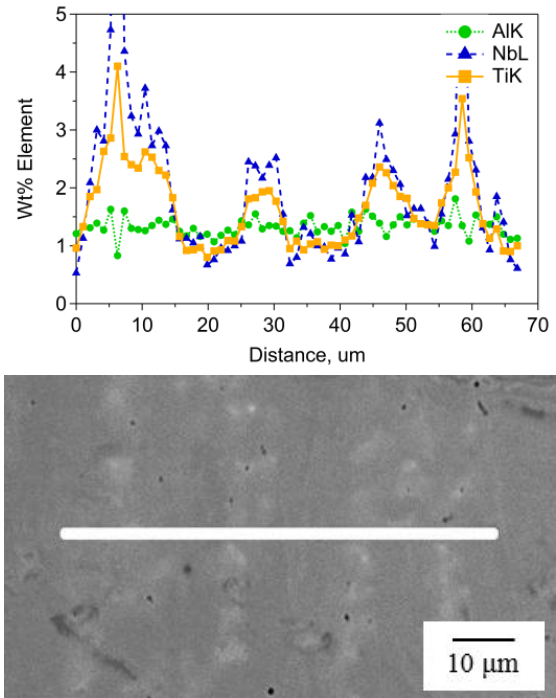

Figure 6. XEDS results for $740 \mathrm{H}$ weld metal.

Table III. Comparison of calculated and experimental partition coefficients for Alloy $740 \mathrm{H}$. Experimental partition coefficients were determined by dividing the XEDS-measured dendrite core composition by the nominal composition.

\begin{tabular}{rcc}
\hline & ThermoCalc & Experimental \\
\hline $\mathbf{A l}$ & 1.01 & 0.81 \\
$\mathbf{N b}$ & 0.21 & 0.46 \\
$\mathbf{T i}$ & 0.51 & 0.66 \\
\hline
\end{tabular}




\section{Discussion}

Solidification analysis has shown that all of the filler metals have very similar solidus temperatures and that the solidification temperature ranges are comparable. Based on this analysis, there is no obvious advantage of any of the filler metals with respect to solidification cracking resistance. The STRs are in the range of $150-180^{\circ} \mathrm{C}$ which would be considered moderate to high as compared to other Ni-base alloys [10].

The hardness data (Figure 4) also does not differentiate the filler metals, with the direct aging response of all weld metals statistically similar. However, the hardness data does show that the direct age heat treatment increases weld metal hardness to base metal hardness levels. This is probably due to slight overaging of the base metal during PWHT. While the direct age PWHT produces an acceptable hardness profile relative to the base metal, it should be noted that this is also the heat treatment that produced unsatisfactory creep rupture data.

The partition coefficients also showed little difference among filler metals (Figure 5). It should be noted that the alloying elements are grouped into partition coefficient regimes. Many alloying elements $(\mathrm{Al}, \mathrm{Fe}, \mathrm{Co}, \mathrm{Cr}, \mathrm{k} \approx 1)$ do not have a strong tendency to segregate and should be found distributed homogenously across the dendritic microstructure. Some elements have a moderate $(\mathrm{Mo}, \mathrm{Ti}, \mathrm{Si}, \mathrm{k} \approx 0.5)$ and others a very strong tendency to segregate $(\mathrm{Nb}, \mathrm{C}, \mathrm{B}, \mathrm{k}<0.2)$. Interdendritic regions will be enriched in the elements that segregate strongly, as shown in the XEDS data in Figure 6.

Since primary strengthening of these filler metals is by gammaprime, $\mathrm{Ni}_{3}(\mathrm{Al}, \mathrm{Ti})$, precipitation, segregation of $\mathrm{Al}$ and $\mathrm{Ti}$ would be expected to affect the local hardening characteristics of the weld metal. Examination of actual $740 \mathrm{H}$ weld metal subjected to creep testing at $700^{\circ} \mathrm{C}$ provides some evidence of this, as shown in Figure 7.

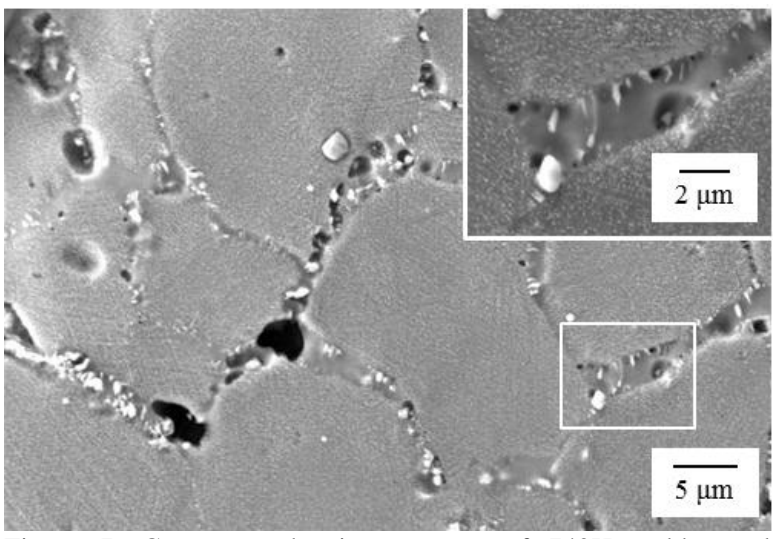

Figure 7. Creep tested microstructure of $740 \mathrm{H}$ weld metal showing a $\gamma$ '-free zone [4]. Note the proximity and morphology of precipitates near the $\gamma^{\prime}$-free zone.

This micrograph was taken near the failure location in a creep test sample. Note the presence of some creep-related voids at the dendrite boundaries. The inset micrograph shows a $\gamma^{\prime}$-free zone at one of these boundaries and was characteristic of the entire sample. The presence of these $\gamma^{\prime}$-free zones is believed to play a significant role in reducing the creep rupture performance of this weld metal.

Microstructural evaluation of $740 \mathrm{H}$ weld metal after direct aging also revealed $\gamma$ '-free zones, although they were not as welldeveloped as those found in the creep specimens. An example is shown in Figure $8 . \quad \gamma^{\prime}$-free zones were generally found to be associated with precipitates of an appreciable aspect ratio. The precipitates form at the end of solidification along the cell/dendrite boundaries. Based on segregation data and XEDS results, these precipitates are most likely $(\mathrm{Ti}, \mathrm{Nb})$-rich carbides. Despite the segregation of the Ti to the boundaries, the formation of these carbides depletes the boundary in $\mathrm{Ti}$ and reduces the tendency for $\gamma^{\prime}$ precipitation. Since Al either does not segregate or segregates in the opposite direction, the availability of $\mathrm{Ti}$ and $\mathrm{Al}$ for $\gamma^{\prime}$ precipitation during direct aging is severely restricted.

This is an extremely important finding since the (Ti,Nb)-rich carbides are quite stable and do not dissolve during solution annealing heat treatments.

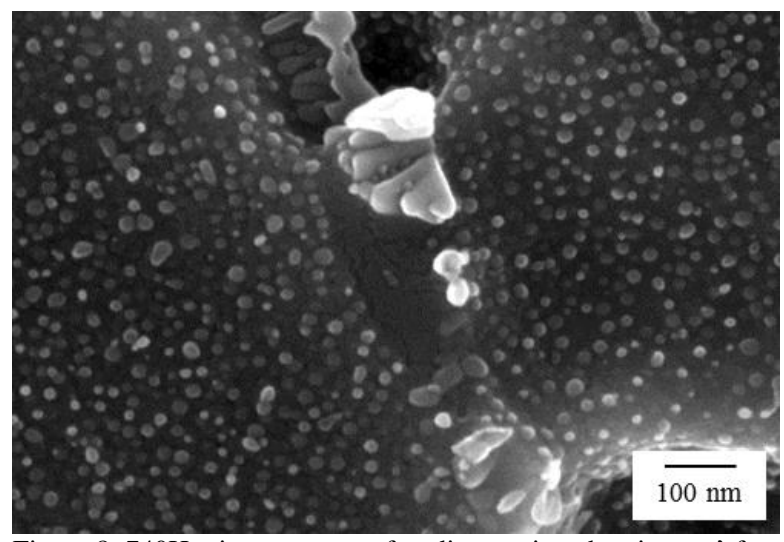

Figure $8.740 \mathrm{H}$ microstructure after direct aging showing a $\gamma$ '-free zone at the dendrite boundary.

In general, the $\gamma^{\prime}$-free zones are associated with (Ti,Nb)-rich carbides that form at the dendrite boundaries. Even at boundaries where these carbides are not present, there is a notable difference in $\gamma^{\prime}$ distribution between dendrite cores and boundaries after the direct aging heat treatment. Figure 9 compares micrographs representing such cases which show a heterogeneous $\gamma^{\prime}$ distribution and the effect of partitioning. It should be noted that the dense $\gamma^{\prime}$ distribution near a dendrite boundary is not near a $(\mathrm{Ti}, \mathrm{Nb}) \mathrm{C}$ precipitate. This observation further supports the previously determined partition coefficients. As indicated in Table IV, two-step heat treatments, especially with one step above the $\gamma^{\prime}$ solvus $\left(\sim 1000^{\circ} \mathrm{C}\right)$, improve the homogeneity of $\gamma^{\prime}$ in the weld metal microstructure. While a complete discussion of these results will not be found here, it should be noted that a different approach to improving weld metal strength, such as filler metal selection or composition modification, should be investigated. 

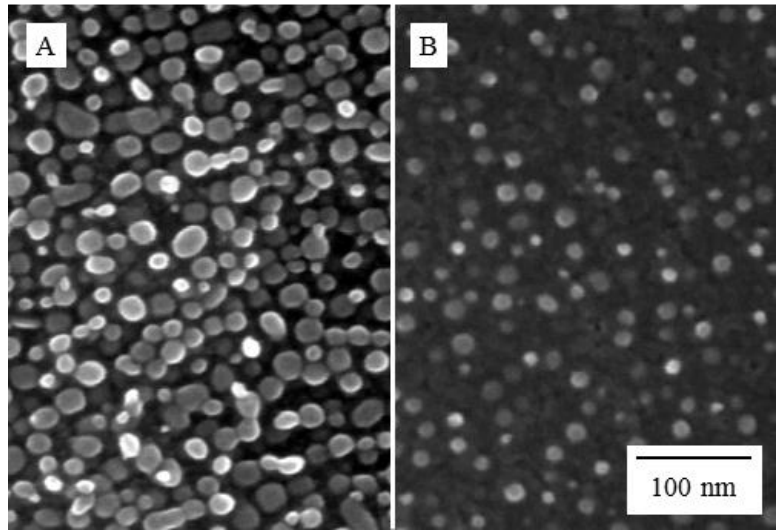

Figure 9. $\gamma^{\prime}$ distribution of dendrite boundaries (A) and cores (B), for $740 \mathrm{H}$ weld metal after $800^{\circ} \mathrm{C} / 4 \mathrm{~h}$. While (A) is near a dendrite boundary, it is far from a (Ti,Nb)C precipitate.

Table IV. Effect of heat treatment on $\gamma^{\prime}$ distribution.

\begin{tabular}{lll}
\hline Heat Treatment & $\gamma^{\prime}$ distribution & $\gamma^{\prime}$-free zones \\
\hline As-Welded & - & - \\
Direct Age & Heterogeneous & Narrow \\
Light Anneal + Age & Homogenous & Medium \\
'Solution' Anneal + Age & Homogenous & Wide \\
High T Anneal & Heterogeneous & Narrow \\
\hline
\end{tabular}

\section{Conclusions}

1. Average solidification temperature ranges for Ni-base filler metal $740 \mathrm{H}$, and filler metals 282 and 263 diluted by Alloy $740 \mathrm{H}$, are all in the range of $150-180^{\circ} \mathrm{C}$.

2. Dilution of filler metals 282 and 263 by Alloy $740 \mathrm{H}$ base metal had little effect on solidification behavior and solidification temperature range.

3. Calculated solidification partition coefficient values were similar for all the filler metals and showed little tendency for $\mathrm{Al}$ partitioning and moderate partitioning of $\mathrm{Ti}$ to dendrite boundaries. $\mathrm{Nb}$ was found to segregate strongly in Alloy $740 \mathrm{H}$.

4. The presence of $\gamma^{\prime}$-free zones was observed in Alloy $740 \mathrm{H}$ weld metal following direct aging. These zones were associated with the precipitation of $(\mathrm{Ti}, \mathrm{Nb})$-rich carbides which form at the end of solidification.

5. At dendrite boundaries where no carbides were present, the $\gamma$ ' density was higher than at other regions of the microstructure due to Ti segregation during solidification.

6. $\quad \gamma$ '-free zones were also observed in creep-tested $740 \mathrm{H}$ weld metal and were the preferred location for creep void formation.

\section{References}

1. R. Viswanathan, et al., "US Program on Materials Technology for Ultra-Supercritical Coal Power Plants," Journal of Materials Engineering and Performance, 14 (3) (2005), 281-292.

2. J. Zachary, "Options for Reducing a Coal-Fired Plant's Carbon Footprint, Part II," Power Magazine, July (2008), 5.

3. S.Q. Zhao, et al., "Research and Improvement on Structure Stability and Corrosion Resistance of Nickel-Base Superalloy INCONEL Alloy 740," Materials \& Design, 27 (10) (2006), 1120-1127.

4. J.A. Siefert, private communication with author, The Ohio State University, 27 September 2010.

5. J. Phillips, "U.S. Program for Advanced Ultrasupercritical Coal Fired Power Plants" (McIlvaine Company "Hot Topic" Webcast: Next Generation of Coal Combustion Technologies, 2011).

6. C.J. Cowen, P.E. Danielson, and P.D. Jablonski, "The Microstructural Evolution of Inconel Alloy 740 During Solution Treatment, Aging, and Exposure at $760{ }^{\circ} \mathrm{C}, "$ Journal of Materials Engineering and Performance, 20 (6) (2011), 1078-1083.

7. B.T. Alexandrov, et al., "Non-equilibrium Phase Transformation Diagrams in Engineering Alloys" (8th International Trends in Welding Research Conference, Plain Mountain, GA, 2008).

8. B.T. Alexandrov, and J.C. Lippold, "Single Sensor Differential Thermal Analysis of Phase Transformations and Structural Changes during Welding and Postweld Heat Treatment," Welding in the World, 51 (11) (2007), 48-59.

9. G.D. Smith, B.A. Baker, and L.E. Shoemaker, "The Development of Inconel Alloy 740 for use as Superheater Tubing in Coal Fired Ultra Supercritical Boilers" (4th Annual Conference on Advances in Materials Technology for Fossil Power Plants, Hilton Head, VA, 2004)

10. J.N. DuPont, J.C. Lippold, and S.D. Kiser, Welding Metallurgy and Weldability of Nickel-Base Alloys (Hoboken, N.J. John Wiley \& Sons, 2009) 108 - 109.

\section{Acknowledgements}

The authors would like to thank Babcock and Wilcox for supporting this work through the NSF I/UCRC - Center for Integrated Materials Joining Science for Energy Applications (CIMJSEA). We also thank Jim Tanzosh and Joe Dierksheide of Babcock and Wilcox, John Siefert (EPRI), and Brian Baker (Special Metals) for providing valuable insight and support. 